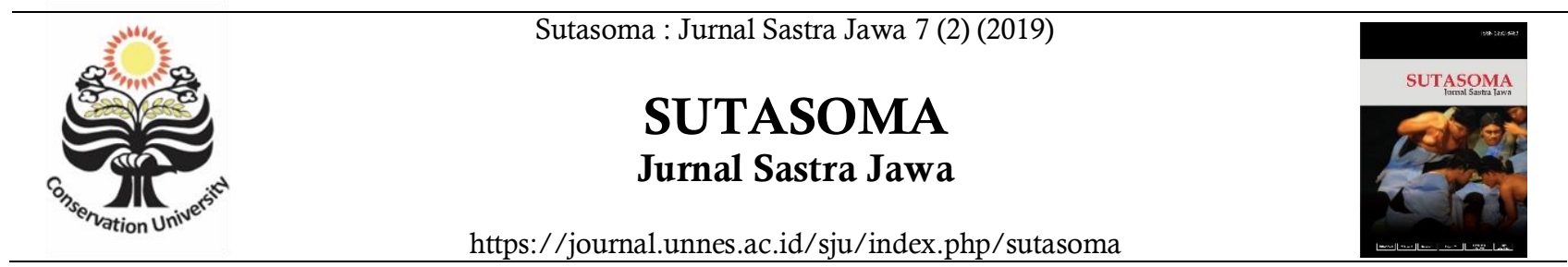

\title{
Satuan Lingual dalam Pembuatan Batu Bata Merah di Desa Jatilaba Kabupaten Tegal (Kajian Etnolinguistik)
}

\author{
Bukhori Fikri, ${ }^{1}$ Ermi Dyah Kurnia, S.S., M.Hum. ${ }^{2}$
}

${ }^{1,2}$ Jurusan Bahasa dan Sastra Jawa, Fakultas Bahasa dan Seni, Universitas Negeri Semarang, Indonesia Corresponding Author: bukhorifikri518@gmail.com

\begin{abstract}
Abstrak
Desa Jatilaba merupakan salah satu daerah di Kabupaten Tegal yang dikenal sebagai penghasil batu bata. Banyak faktor yang mempengaruhi hasil dari pembuatan termasuk bahan, cara, lokasi, hingga tenik pembuatan berupa satuan lingual. Tujuan dalam penelitian ini adalah mendeskripsikan bentuk satuan lingual, mendeskripsikan makna satuan lingual, dan mendeskripsikan fungsi satuan lingual dalam pembuatan batu bata merah. Analisis data dilakukan menggunakan teknik analisis bahasa secara struktural dan etnolinguistik terhadap satuan lingual yang digunakan. Hasil analisis adalah satuan lingual berbentuk kata yang terdapat pada pembuatan batu bata merah di Desa Jatilaba Kabupaten Tegal berupa: kata dasar, kata turunan, dan kata majemuk. Selain itu, terdapat satuan lingual berbentuk frasa yang digolongkan berdasarkan distribusi, kategori inti, dan satuan lingual unsurunsurnya. Makna satuan lingual dianalisis berdasarkan makna leksikal dan makna kultural. Makna leksikal satuan lingual dibagi berdasarkan beberapa makna, antara lain berdasarkan bahan, alat, aktivitas, dan hasil aktivitas. Fungsi satuan lingual yang ditemukan sebagai alat komunikasi, sebagai penghubung dunia gaib, sebagai wujud pemanfaatan sumber daya alam, menunjukkan asal nama proses dari alat yang digunakan, menunjukkan asal nama proses dari suara yang dihasilkan, menunjukkan asal nama proses dari hasil yang diperoleh, pemanfaatan teknologi, menggambarkan teknik membuat batu bata merah yang benar, dan sebagai ajaran turun temurun.
\end{abstract}

Kata Kunci: satuan lingual, makna, etnolinguistik, dan fungsi.

\begin{abstract}
Jatilaba village is one of the areas in Tegal Kabupaten which is known as a producer of bricks. Many factors affect the results of the manufacture, including materials, methods, location, and manufacturing practices in the form of lingual units. The objectives of this study are describing the form of the lingual unit, describing the meaning of the lingual unit, and describing the function of the lingual unit in the red brick manufacture. Data analysis was performed using structural and ethnolinguistic language analysis techniques for the lingual unit used. Based on the results of the analysis, lingual units in the form of words found are basic words, derived words, and compound words. In addition to that, there are lingual units in the form of phrases classified according to the distribution, core categories, and lingual units of the elements. The meaning of the lingual unit in the red bricks manufacture in Jatilaba Village, Tegal Regency is analyzed based on its lexical and cultural meanings. The lexical meaning of the lingual unit is divided based on several meanings, namely, based on tools, material, activities, and results of activities. The lingual unit function found is as a communication tool, as a link to the supernatural world, as a form of utilization of natural resources, indicating the origin of the process name of the instrument used, indicating the origin of the process name from the sound produced, indicating the origin of the process name from the results obtained, utilizing technology, describing the technique of making true red bricks, and as hereditary teachings.
\end{abstract}

Keywords: lingual unit, meaning, ethnolinguistics, and function.

(C) 2019 Universitas Negeri Semarang

p-ISSN 2252-6463 e-ISSN 2686-5408 


\section{PENDAHULUAN}

Desa Jatilaba merupakan suatu lokasi pembuatan batu bata merah wilayah dataran rendah di Kecamatan Margasari Kabupaten Tegal. Hasil batu bata merah Desa Jatilaba dikenal baik dan berkualitas. Hal ini dipengaruhi oleh beberapa faktor seperti lokasi pembuatan, bahan dan alat yang digunakan, cuaca penentuan masa, cara pengolahan, cara perawatan, dan cara perlakuan pasca pembakaran. Selain faktor alam, faktor teknik juga berpengaruh dengan hasil yang diperoleh. Teknik tersebut tergambar dalam satuan lingual yang digunakan pada pembuatan. Satuan lingual merupakan satuan dalam struktur bahasa (Kridalaksana, 1982:148). Satuan lingual ditemukan dalam beberapa golongan antara lain pada bahan yang digunakan, alat yang digunakan, dan aktivitas pembuatan beserta hasil aktivitasnya.

Satuan lingual tersebut merupakan perwujudan dari hasil pemikiran masyarakat petani yang sudah ada sejak dahulu. Sebagian besar diwariskan secara turun temurun, sehingga masih digunakan hingga sekarang dengan mengalami perkembangan jaman, sesuai sifat bahasa yang dinamis. Objek lain yang memiliki keunikan dan perlu dilestarikan terkait nilai kebudayaannya yakni petani pembuat batu bata di desa Jatilaba masih mempercayai adanya hal mistis seperti menyediakan sesajen untuk disajikan kepada roh nenek moyang atau makhluk halus yang ada di sekitar. Hal tersebut sebagai bentuk penghormatan dan harapan agar tidak diganggu selama proses pembakaran, sekaligus sebagai bentuk harapan agar di beri kelancaran, keberkahan, dan kesejahteraan. Selain itu, ada kebiasaan yaitu pembuatan batu bata merah di Desa Jatilaba Kabupaten Tegal selalu dibuat di mangsa ketiga [mansa kətiga] 'musim panas'.

Berdasarkan latar belakang tersebut, peneliti tertarik untuk meneliti dan mengkaji satuan lingual dalam pembuatan batu bata merah di Desa Jatilaba Kabupaten Tegal dari segi Etnolinguistik. Foley
(2001:3) berpendapat bahwa etnolinguistik adalah ilmu yang mempelajari bahasa berdasarkan konsep antropologi, kebudayaan, dan juga untuk mengungkapkan makna yang tersembunyi di balik penggunaannya oleh suatu masyarakatnya. Goodenough (1964:36) menyatakan bahwa bahasa dan kebudayaan memiliki hubungan yang sangat erat. Suatu kebudayaan tidak dapat berkembang tanpa bahasa dan bahasa itu hidup di dalam suatu kebudayaan yang mana kebudayaan itu dimiliki oleh suatu masyarakat. Etnoinguistik adalah cabang linguistik yang dapat digunakan untuk menyelidiki hubungan antara bahasa dan budaya masyarakat di pedesaan atau masyarakat yang belum memiliki tulisan, akan tetapi definisi tersebut meluas seiring dengan perkembangan zaman yang semakin sedikit jumlah masyarakat pedesaan yang belum mempunyai tulisan (Kridalaksana, 2001:52).

Masalah dibatasi mengenai bentuk, makna, dan fungsi satuan lingual dalam pembuatan batu bata merah di Desa Jatilaba Kabupaten Tegal berdasarkan kronologi teknik membuat batu bata merah dengan baik dan benar yang mencakup: (1) bahan yang digunakan, (2) alat yang digunakan, (3) aktivitas pembuatan, dan (4) hasil dari aktivitas pembuatan.

\section{METODE PENELITIAN}

Penelitian menggunakan pendekatan metodologis berupa pendekatan deskriptif-kualitatif dan pendekatan teoretis berupa pendekatan etnolinguistik, pendekatan semantik, dan pendekatan struktur bahasa. Data dalam penelitian yaitu satuan lingual yang digunakan dalam pembuatan batu bata merah di Desa Jatilaba Kabupaten Tegal. Sumber data adalah hasil observasi lapangan dan wawancara mendalam dengan informan (berupa tuturan petani pembuat batu bata). Data diperoleh menggunakan teknik wawancara, teknik simak, teknik catat, dan 
teknik dokumentasi. Analisis data menggunakan teknik analisis bahasa struktural dan etnolinguistik terhadap satuan lingual yang digunakan, serta teknik formal dan informal digunakan sebagai teknik penyajian hasil analisis data.

\section{HASIL DAN PEMBAHASAN}

\section{Satuan Lingual dalam Pembuatan Batu Bata Merah di Desa Jatilaba Kabupaten Tegal}

Proses panjang petani pembuat batu bata untuk menghasilkan bata merah berkualitas tinggi melibatkan berbagai macam kegiatan aktivitas, pengolahan lahan, faktor internal dan eksternal, peralatan pendukung. Bahasa sebagai ujung tombak terjadinya komunikasi dua arah dibutuhkan sebagai pengkode atau penanda konvensional untuk menamai berbagai macam aktivitas, peralatan, bahan, dan lain sebagainya, sehingga terciptalah satuan lingual dalam pembuatan batu bata merah di Desa Jatilaba Kabupaten Tegal. Satuan lingual tersebut ditemukan dan dikumpulkan sebanyak 34 satuan lingual yang kemudian dianalisis berdasarkan bentuk, makna, dan fungsinya.

\section{Bentuk Satuan Lingual}

Satuan lingual pembuatan batu bata merah di Desa Jatilaba Kabupaten Tegal yang ditemukan berbentuk kata dan frasa. Satuan lingual yang berbentuk kata ditemukan sebanyak 24 satuan lingual yang digolongkan menjadi 3, antara lain: (1) kata dasar sebanyak 5 satuan lingual, (2) kata turunan sebanyak 16 satuan lingual, dan (3) kata majemuk sebanyak 3 satuan lingual. Satuan lingual yang berbentuk frasa ditemukan sebanyak 10 satuan lingual yang digolongkan menjadi 3, yaitu: (1) frasa berdasarkan distribusi, (2) frasa berdasarkan kategori inti, dan (3) frasa berdasarkan satuan unsur-unsur.

\section{Bentuk Kata}

Satuan lingual yang ditemukan dalam bentuk kata dasar terdiri atas satu kata yang tidak diikuti afiksasi dan tidak dapat dibagi lagi menjadi lebih kecil. Berdasarkan distribusinya dapat digolongkan sebagai morfem bebas karena dapat berdiri sendiri sebagai kata. Berdasarkan satuan gramatiknya, digolongkan dalam bentuk monomorfemis karena terdiri atas satu morfem. Satuan lingual yang berbentuk kata dasar yaitu dami, cokbang, garok [garok], diklet, dan dligen.

Satuan lingual yang berbentuk kata turunan terdiri atas dua morfem. Morfem tersebut berasal dari morfem bebas dan morfem terikat. Satuan lingual berbentuk kata turunan yang ditemukan berupa proses afiksasi, yaitu prefiks nasal ( $n y$-, $m$-, $n g-, n$ ), sufiks - an, dan konfiks (nasal ny-/$i$, nasal $m-/-i$, nasal $n g-/-i$, dan nasal $n-/-i$ ). Berdasarkan satuan gramatiknya, digolongkan dalam bentuk polimorfemis karena terdiri atas dua morfem. Satuan lingual yang berbentuk kata turunan adalah: cithakan, gedhigan, nyonggah, ngesrogi, nggedhig, ngluluh, nyithak, nyrucuk, ngepeh, nyisik, ngetap, nglepah, nyajeni, medhang, ngunjal, dan tap-tapan.

Satuan lingual yang berbentuk kata majemuk terdiri atas dua kata yang saling berhubungan secara padu membentuk arti dan makna baru dan tidak dapat dipisahkan karena akan kehilangan maknanya. Satuan lingual yang ditemukan dalam bentuk kata majemuk terdiri dari dua kata yang tidak diikuti afiksasi dan terdapat satu majemuk yang salah satu katanya mengalami reduplikasi. Berdasarkan satuan gramatiknya, digolongkan dalam bentuk polimorfemis karen terdiri atas dua morfem. Satuan lingual yang berbentuk kata majemuk, adalah: juadah pasar, tumpiang angin dan arang-arang kambang . 


\section{Bentuk Frasa}

Berdasarkan distribusi, satuan lingual yang ditemukan dalam bentuk frasa yaitu frasa endosentrik sebanyak 10 satuan lingual. Frasa endosentrik adalah frasa yang salah satu unsurnya atau komponennya mempunyai perilaku sintaksis yang sama dengan keseluruhannya sehingga salah satu komponennya itu dapat menggantikan kedudukan keseluruhannya (Chaer, 1994:226). Satuan lingual yang berbentuk frasa endosentrik adalah: lemah persil, gedhang pitu rupa, gedhang raja, rokok srutu, dhawegan klapa ijo, rujak srobo, sega penggel, pethek pirik, bubur abang putih, jajan moho abang putih, dan ngejib bata.

Berdasarkan kategori inti, satuan lingual yang ditemukan dalam bentuk frasa dibedakan menjadi empat, yaitu frasa nomina sebanyak 10 satuan lingual dan frasa verba sebanyak 1 satuan lingual. Frasa nomina adalah frasa yang unsur intinya berwujud nomina (kata benda). Satuan lingual yang berbentuk frasa nomina adalah: lemah persil, gedhang pitu rupa, gedhang raja, rokok srutu, dhawegan klapa ijo, rujak srobo, sega penggel, pethek pirik, bubur abang putih, dan jajan moho abang putih. Frasa verba adalah frasa yang unsur intinya berwujud verba (kata kerja). Satuan lingual yang berbentuk frasa verba adalah ngejib bata [nәjIb bata].

Berdasarkan satuan lingual unsur- unsur, satuan lingual yang ditemukan dalam bentuk frasa dibedakan menjadi tiga struktur frasa, yaitu frasa berstruktur kata dan kata sebanyak 7 satuan lingual yakni: lemah persil, gedhang raja, rokok srutu, rujak srobo, sega penggel, pethek pirik, dan ngejib bata; frasa berstruktur kata dan frasa sebanyak 3 satuan lingual yakni gedhang pitu rupa, dhawegan klapa ijo, dan bubur abang putih; dan frasa berstruktur frasa dan frasa sebanyak 1 satuan lingual yakni jajan moho abang putih.

\section{Makna Leksikal Satuan Lingual dalam Pembuatan Batu Bata Merah Di Desa Jatilaba Kabupaten Tegal}

Satuan lingual dalam pembuatan batu bata merah di Desa Jatilaba Kabupaten Tegal yang ditemukan dan dikumpulkan, dianalisis menggunakan makna leksikal yang dapat dibedakan menjadi 4, yaitu berdasarkan bahan sebanyak 14 satuan lingual yaitu: dami, juadah pasar, gedhang pitu rupa, gedhang raja, rokok srutu, tumpiang angin, arang-arang kambang, dhawegan klapa ijo, rujak srobo, sega penggel, pethek pirik, bubur abang putih, jajan moho abang putih, dan cokbang; berdasarkan alat sebanyak 5 satuan lingual yaitu garok, cithakan, gedhigan, diklet, dan dligen; berdasarkan aktivitas sebanyak 14 satuan lingual yaitu nyonggah, nggedhig, ngluluh, nyitha, nyrucuk, ngepeh, nyisik, ngetap, ngejib bata, nglepah, nyajeni, medhang, dan ngunjal; dan berdasarkan hasil aktivitas sebanyak 1 satuan lingual.yaitu tap-tapan Makna leksikal merupakan makna yang ada dan dimiliki oleh leksem meski tidak dengan konteks apapun (Chaer, 1994:289).

Contoh analisis makna leksikal satuan lingual yang tergolong dalam bahan adalah dami. Dami adalah batang padi yang sudah mengering dan dihasilkan setelah panen padi. Contoh analisis makna leksikal satuan lingual yang tergolong dalam alat adalah garok [garok]. Garok merupakan alat yang terbuat dari lempengan kayu berbentuk pipih persegi panjang dengan gagang kayu yang panjang. Garok digunakan untuk mengumpulkan tanah yang tersebar sehingga akan mempermudah dalam pengambilan tanah dan juga digunakan untuk membersihkan dan ikut meratakan permukaan tanah yang akan digunakan sebagai tempat pencetakan batu bata. Contoh analisis makna leksikal satuan lingual yang tergolong dalam aktivitas adalah nyithak [ñițak]. Nyithak merupakan proses pencetakan batu bata yang dilakukan langsung di tempat pembuatan batu bata merah baik lahan pertanian sawah maupun lahan pertanian 
persil. Contoh analisis makna leksikal satuan lingual yang tergolong dalam hasil aktivitas adalah tap-tapan. Tap-tapan merupakan hasil penataan batu bata baik yang sudah kering maupun yang masih setengah kering.

\section{Makna Kultural Satuan Lingual dalam Pembuatan Batu Bata Merah di Desa Jatilaba Kabupaten Tegal}

Berdasarkan analisis makna kultural, satuan lingual yang ditemukan sebanyak 16 yaitu: juadah pasar, gedhang pitu rupa, gedhang raja, rokok srutu, tumpiang angin, arang-arang kambang, dhawegan klapa ijo, rujak srobo, sega penggel, pethek pirik, bubur abang putih, jajan moho abang putih, cokbang [cokbay], ngluluh, ngejib bata, nyajeni [ñajeni], dan ngunjal. Satuan lingual tersebut mengandung makna hubungan antara manusia dengan Tuhannya, makhluk gaib, dan sesama manusia, seperti pada contoh satuan lingual nyajeni 'aktivitas menyediakan sesajen' dan ngunjal 'aktivitas mengangkat dan memindahkan batu bata'. Aktivitas nyajeni dalam pembuatan batu bata merah, masyarakat menyediakan sesajen untuk disajikan kepada roh nenek moyang atau makhluk halus yang ada di sekitar sebagai bentuk penghormatan dan harapan agar tidak diganggu selama proses pembakaran batu bata berlangsung. Selain itu, juga sebagai bentuk harapan kepada Tuhan yang maha kuasa agar di beri kelancaran, keberkahan, dan kesejahteraan. Aktivitas ngunjal dalam pembuatan batu bata dilakukan dengan bergotong royong karena batu bata merah yang diangkat dan dipindahkan jumlahnya sangat banyak. Gotong royong ini dimaknai bahwa kehidupan manusia harus bergotong royong, tolong menolong, dan saling bantu karena pada hakikatnya manusia hidup saling membutuhkan antar sesama.

\section{Fungsi Satuan Lingual dalam Pembuatan Batu Bata Merah di Desa Jatilaba Kabupaten Tegal}

Satuan lingual adalah salah satu komponen bahasa yang memiliki peran tersendiri yang disesuaikan dengan penggunaanya. Satuan lingual yang digunakan dalam pembuatan batu bata merah di Desa Jatilaba Kabupaten Tegal memiliki beberapa fungsi, antara lain: sebagai alat komunikasi, sebagai penghubung dunia gaib dan dunia nyata, sebagai wujud pemanfaatan sumber daya alam, menunjukkan asal nama proses dari alat yang digunakan, menunjukkan asal nama proses dari suara yang dihasilkan, menunjukkan asal nama proses dari hasil yang diperoleh, pemanfaatan teknologi, penggambarkan teknik membuat batu bata merah yang benar, dan sebagai ajaran secara turun-temurun. Fungsi sebagai alat yaitu sebagai bentuk penghormatan kepada Tuhan yang Maha Esa dan penghormatan kepada roh nenek moyang atau penghormatan yang menyambungkan hubungan keharmonisan dengan bangsa gaib yang turut andil dalam pembuatan batu bata merah dan dalam menjaga proses pembakaran batu bata. Satuan lingual yang berfungsi sebagai alat komunikasi yaitu dawegan klapa ijo yang merupakan salah satu sajian sesajen yang dimaksudkan untuk disajikan khusus para wali. Kata dawegan diambil dari kata seadegan yang memiliki arti menjalan shalat. Jadi, dawegan klapa ijo ini memerintahkan kita untuk shalat dan berserah diri kepada Tuhan yang Maha Kuasa.

Fungsi sebagai penghubung dunia gaib dan dunia nyata yaitu fungsi satuan lingual yang ada pada sajian sesajen dalam proses nyajeni yang menjadi simbol mengutarakan maksud dan tujuan melalui sarana sesaji tersebut diharapkan dapat diterima dan dipahami oleh mereka yang berada dan mendiami dunia gaib. Fungsi sebagai wujud pemanfaatan sumber daya alam yaitu masyarakat desa Jatilaba tetap mempertahankan wilayah lahan pertaniannya sebagaI 
sumber pangan. Seperti memanfaatkan lemah persil yang ditemukan di lahan pertanian persil. Lemah persil ini akan menghasilkan batu bata merah yang sangat bagus, karena kedua macam tanah ini memiliki tanah gembur dan tekstur liat yang tidak terlalu padat sehingga sangat bagus dijadikan sebagai bahan pembuatan batu bata merah. Fungsi yang menunjukkan asal nama proses dari alat yang digunakan yaitu penamaan proses pembuatan batu bata merah dari alat yang digunakannya menunjukkan asal nama proses dari alat yang digunakan tersebut seperti dalam satuan lingual nyithak menunjukkan aktivitas yang menggunakan alat cithakan dalam pembuatan batu bata merah. Fungsi yang menunjukkan asal nama proses dari suara yang dihasilkan yaitu penamaan proses pembuatan batu bata merah dari suara yang dihasilkan pada saat proses berlangsung menunjukkan asal nama proses dari suara yang dihasilkan tersebut seperti dalam satuan lingual nyrucuk menunjukkan aktivitas yang menghasilkan suara cruk dalam pembuatan batu bata merah. Fungsi yang menunjukkan asal nama proses dari hasil yang diperoleh yaitu penamaan proses pembuatan batu bata merah dari hasil yang akan diperoleh menunjukkan asal nama proses dari hasil yang diperoleh tersebut seperti dalam satuan lingual nama ngetap menunjukkan aktivitas yang menghasilkan tap-tapan dalam pembuatan batu bata merah.

Fungsi pemanfaatan teknologi yaitu memanfaatkan sebuah alat ataupun mesin yang digunakan dalam pembuatan batu bata merah seperti alat yang digunakan untuk memukul, memecahkan, atau melembutkan tanah keras yang masih menggumpal agar lebih mudah untuk diolah ialah alat yang disebut dengan gedhigan [gedigan] 'alat pemukul'. Fungsi penggambaran teknik membuat batu bata merah yang benar yaitu fungsi yang memberikan contoh tentang tata cara membuat batu bata merah yang benar, misalnya ngluluh [ylulUh] yang merupakan proses menginjak-injak tanah yang dicampur dengan dedak padi menggunakan air di dalam sebuah lubag yang dibuat. Proses ngluluh ini memiliki gerakan satu kaki menjadi tumpuan dan satu kaki lagi digerakan dengan menginjak yang sangat kuat. Gerakan kaki tersebut dilakukan terus menerus secara bergantian hingga bahan yang dicampurkan menyatu rata dan halus. Fungsi sebagai ajaran turun temurun yaitu penamaan satuan lingual dan budaya yang diberikan dari orang-orang terdahulu. Masyarakat hingga kini menyebutnya seperti yang dulu diberikan dan akan terus menggunakan istilah tersebut. Begitu pula dengan kebiasaan masyarakat yang dilakukan dalam pembuatan batu bata merah seperti budaya pada saat pembakaran batu bata yang akan dan sedang berlangsung hingga batu bata telah matang yakni tradisi nyajeni juga masih tetap dilaksanakan karena merupakan ajaran secara turun temurun.

\section{SIMPULAN}

Berdasarkan hasil analisis data disimpulkan tiga hal. Pertama, satuan lingual dalam pembuatan batu bata merah di Desa Jatilaba Kabupaten Tegal terdiri atas kata dan frasa. Kata diklasifikasi berdasarkan kata dasar, kata turunan, dan kata majemuk, sedangkan frasa diklasifikasikan berdasarkan distribusinya, kategori intinya, dan satuan lingual unsur-unsurnya. Kedua, satuan lingual dalam pembuatan batu bata merah di Desa Jatilaba Kabupaten Tegal memiliki makna. Makna dalam penelitian ini diklasifikasikan berdasarkan makna leksikal. Makna leksikal diklasifikasi berdasarkan penentuan masa, alat, bahan, aktivitas, dan hasil aktivitas. Ketiga, fungsi satuan lingual dalam pembuatan batu bata merah di Desa Jatilaba Kabupaten Tegal sebagai alat komunikasi, sebagai penghubung dunia gaib dan dunia nyata, sebagai wujud pemanfaatan sumber daya alam, menunjukkan asal nama proses dari alat yang 
digunakan, menunjukkan asal nama proses dari suara yang dihasilkan, menunjukkan asal nama proses dari hasil yang diperoleh, pemanfaatan teknologi, penggambarkan teknik membuat batu bata merah yang benar, dan sebagai ajaran secara turun-temurun.

\section{DAFTAR PUSTAKA}

Baehaqie, Imam. 2013. Etnoliguistik Telah Teoretis dan Praktis. Surakarta: Cakrawala Media

Chaer, Abdul. 1994. Linguistik Umum.Jakarta: Rineka Cipta.

Chaer, Abdul. 2002. Pengantar Semantik Bahasa Indonesia. Jakarta: Rineka Cipta.

Foley, W. 2001. Anthropological Linguistics: An Introduction. GB: Blackwell.

Goodenough, W. 1964. Cultural Anthropology and Linguistics in Hymes, D. New York: Harper\& Row.

Harimurti, Kridalaksana. 1983. Kamus Linguistik. Jakarta: Gramedia Pustaka Utama.

Harimurti, Kridalaksana. 2001. Kamus Linguistik. Jakarta: Gramedia Pustaka Utama.

Pateda, Mansoer. 2001. Semantik Leksikal. Jakarta: Rineka Cipta.

Ramlan, M. 1987. Morfologi: Suatu Tinjauan Deskriptif. Yogyakarta: CV. Karyono. 